\title{
Indios andinos en cofradías chilenas (Santiago, siglo XVII)*
}

\author{
Jaime ValenZuela MárQuez
}

\section{RESUMEN}

Desde las expediciones de conquista hasta el flujo migratorio individual que se desarrolló durante el siglo XVII, numerosos indígenas andinos se instalaron en Santiago. Varios dictaron testamentos y dejaron huellas en documentos eclesiásticos que nos permiten observar su participación en las cofradías

* Ponencia presentada en el vil Congreso Internacional de Etnohistoria (Lima, 4-7 de agosto de 2008). Este trabajo forma parte del proyecto de investigación «Inmigrantes indígenas. Indios cuzcos y huarpes en Chile colonial (siglos XVI-XVII)", financiado por Fondecyt (n. $\left.{ }^{\circ} 1070451,2007-2010\right)$. Agradecemos la colaboración de Hugo Contreras y Patricia Palma. 
religiosas de la ciudad. Estas se pueden ver, a su vez, como un canal preferente para la sociabilidad y la religiosidad contrarreformista $y$, al mismo tiempo, como un espacio privilegiado para la inserción y movilidad social de población diversa. En efecto, no solo andinos, sino también huarpes, juríes y mapuches, además de mestizos, africanos e hispanocriollos de diversa procedencia y jerarquía, fueron diseñando una sociedad urbana crecientemente pluriétnica y multicultural, que tuvo eco, también, en la conformación de las cofradías santiaguinas, lo cual complejizó la experiencia religiosa, social y cultural que se producía en su interior.

Palabras Clave: cofradías, Chile, indígenas, inmigrantes, etnicidad, siglo XVII

\section{INTRODUCCIÓN}

SIGUIENDO LA TRADICIÓN MEDIEVAL que subyacía a las estructuras y a las formas de las prácticas religiosas desplegadas por los españoles en América, la experiencia devocional reproducirá aquí los ribetes corporativos propios del paradigma europeo dominante en la época de la conquista, paradigma que luego será reforzado por la cultura contrarreformista que se desplegará desde fines del siglo XVI.

Las cofradías serán, pues, aquellas instancias privilegiadas para canalizar la devoción de los laicos en el escenario festivo, para intentar un seguimiento tridentino de las prácticas católicas - vinculando la piedad colectiva con las instituciones eclesiásti- 
cas - y para brindar un apoyo espiritual y material a la hora de enfrentar los ritos de la muerte. En esta misma línea, también servirán para cultivar la memoria de los cofrades difuntos - por medio de misas anuales - o para asistir a los miembros activos ante algún problema económico circunstancial (Bazarte 1998).

Junto con ello, las cofradías otorgaban la posibilidad de generar un espacio de sociabilidad para personas vinculadas por lazos sociales, laborales o étnicos. Habrá algunas de gran prestigio - integradas por lo más granado de la élite local_-; otras que refrendaban las redes gremiales de determinadas especialidades artesanales y otras que, en el contexto de la realidad americana, vinculaban a personas clasificadas por el sistema colonial en determinadas categorías étnicas - negros, mulatos, indios, castas, etc. - (Lavrín 1998; Celestino y Meyers 1981a: 121). También habrá, por cierto, cofradías mixtas y plurales, donde convivían y practicaban su religiosidad integrantes de diferente color de piel y de diferente condición social o cultural.

De esta forma, el esquema de cofradías implantado en América tuvo que comprender, además de los criterios profesionales y sociales característicos del mundo europeo, el criterio étnico. La institucionalidad religiosa se impregnaba así del mestizaje sanguíneo y cultural que estructuraba la sociedad colonial, y tanto los neófitos indígenas como los africanos y las castas, fueron incorporados plenamente al sistema de signos y de prácticas desplegadas por la Iglesia en el conjunto de la sociedad. El organigrama de cofradías, entonces, fue lo suficientemente flexible como para diseñar nuevos criterios de selección que incluyesen a los nuevos actores americanos. 
La cofradía era, entonces, para los no hispanocriollos, una institución que aportaba un marco identitario a sus integrantes, una identidad corporativa bajo la cual podían presentarse ante el sistema colonial, definir su nivel de compromiso con él y, por tanto, reivindicar cierto grado de integración simbólica y de prestigio, elementos que podían ostentar frente a la Iglesia, al Estado y a los otros grupos de la sociedad. En otras palabras, ser miembro de una cofradía podía implicar — sobre todo para aquellas personas de grupos sociales o étnicos discriminados o subvalorados - una determinada forma de movilidad social y de reconocimiento, pensando en aquellos que estaban en proceso de integraciớn y ascenso. Para los que ya habían alcanzado estos espacios, podía ayudar a refrendarlos y enriquecerlos con una fuente adicional de posicionamiento sociorreligioso.

De ahí la importancia que tenía para sus miembros - fuesen grandes encomenderos, modestos albañiles, indios urbanos o negros libertos - no solo el pago regular de la cuota que les aseguraba un entierro digno y con las necesarias solemnidades, sino también la participación activa en el calendario litúrgico de la Iglesia. Dentro de este, se daba una especial atención a la fiesta de la advocación tutelar de la corporación —cuya imagen generalmente era venerada en la capilla propia, ubicada al interior del respectivo templo-, saliendo al espacio público con la ostentación de sus mejores ropas y atuendos, y conforme al orden jerárquico de cada uno de sus miembros.

Porque, sin duda, la jerarquía visual — como la social - era una regla fundamental a la hora de descifrar los matices de poder que circulaban entre sus integrantes, poderes que se cristalizaban en 
los cargos de mayordomo - que administraba los ingresos y gastos, organizaba las actividades y servía de nexo con la comunidad religiosa o la autoridad parroquial que la albergaba- $y$ de los veinticuatro, el grupo de mayor influencia, con voto activo y pasivo en las elecciones y en las decisiones de la hermandad. Esta estructura administrativa, por cierto, respondía a las formas tradicionales de las cofradías europeas; sin embargo, observada también en un nivel local, implicaba la reivindicación de prestigios simbólicos y la asignación de espacios de poder horizontal entre pares sociales y étnicos (Chance y Taylor 1985).

Desde la perspectiva de la Iglesia y del Estado, por su parte, estas corporaciones se mostraban funcionales al paradigma corporativo bajo el cual se pretendía organizar a la sociedad colonial. En efecto, ellas permitían —al menos teóricamente — vigilar a los fieles y aplicar las disposiciones eclesiásticas dispuestas por el Concilio de Trento a partir de su implementación americana con el tercer Concilio limense (1582-1583). Por lo demás, el mundo contrarreformista daba una alta validación a la experiencia pública de la devoción, volcada a la calle a través de las procesiones que reforzaban en la práctica — por medio de la experiencia visual y corporal- los avances del adoctrinamiento y de la incorporación a los parámetros conductuales que el sistema colonial definía para los distintos segmentos de la sociedad. Siendo las procesiones uno de los canales tradicionales por medio de los cuales se expresaban las cofradías, estas terminaban siendo una útil herramienta para el proceso de cristianización que se desplegó sobre las poblaciones indígenas; esto último, sobre todo, en el periodo temprano de la postconquista, cuando las cofradías de indígenas pudieron erigirse como nuevas instan- 
cias de cohesión social en el ámbito comunitario, ante el quiebre de los mecanismos tradicionales prehispánicos que delineaban, por ejemplo, las redes de parentesco, de solidaridad y de integración presentes en los ayllus andinos (Celestino y Meyers 1981a: 43, 125 y 126; Celestino y Meyers 1981b: 184).

\section{El CONTEXTO: RELigIOSIDAD y COFRADías EN EL SANTIAGo BarRoco}

Cada una de las órdenes de regulares que poblaron el espacio eclesiástico de la capital chilena se esmeró por apoyar la fundación y ostentar la existencia en su seno de cofradías que, al menos nominalmente, estaban diferenciadas por origen social o étnico, y que se podían ver desfilar por las calles durante la Semana Santa, en Corpus Christi y durante las respectivas festividades anuales de sus santos y advocaciones votivas (Valenzuela Márquez 2001). En el plano propiamente eclesiástico, estas organizaciones servirán para orientar institucionalmente el adoctrinamiento y la preparación para la actuación devocional de los distintos grupos en el calendario litúrgico. Así, a mediados del siglo XVII, el jesuita Alonso de Ovalle describía la participación pública del conjunto de estas organizaciones corporativo-identitarias para la fiesta del Corpus Christi:

Concurren a ésta todas las religiones y cofradías con la solemnidad que se usa en otras partes, y todos los oficios mecánicos con sus estandartes y pendones, de manera que viene a coger muy grande trecho. Después de la procesión de la catedral se siguen las de las religiones y monasterios de monjas, con que vienen a durar todas más de un mes, pro- 
curando cada cual que salga mejor la suya, con mayor ostentación de cera y adorno de andas y altares, los cuales suelen hacerlos muy ricos y vistosos, de curiosas tramoyas y artificios. A todas estas procesiones acuden los indios de la comarca que están en las chacras (que son como aldeas, a una y dos leguas de la ciudad) y trae cada parcialidad su pendón, para el cual eligen algunos días antes el alférez, y éste tiene obligación de hacer fiesta el día de la procesión a los demás de su ahillo (Ovalle 1969 [1646]: 285-287).

Franciscanos, mercedarios, agustinos, dominicos y jesuitas competían permanentemente por acentuar el dramatismo y la originalidad en la participación de las cofradías que dependían de ellos. En este sentido, siempre destacaban, por el espectáculo que brindaban, la cofradías de penitentes que recorrían, azotándose y gimiendo, las principales calles de la ciudad en la noche de Jueves Santo. En estas procesiones de sangre, tres grupos sociales distintos recordaban públicamente el extremo doloroso de la muerte de Cristo: los vecinos y miembros de la élite, que salían desde la capilla de la Veracruz, en el convento mercedario; un grupo numeroso de indígenas, que se organizaba en el convento de San Francisco; y otro menor, de negros, que partía desde la iglesia de los dominicos (Ovalle 1969 [1646]: 289-291). A propósito de los indígenas locales y de su participación en Corpus Christi, por ejemplo, Ovalle señalaba que ellos recorrían las calles inundando el espacio público con su danza y su música, insertos en la gran procesión general que comprendía a todo el universo sociocultural de la ciudad: «Es tan grande el número de esta gente y tal el ruido que hacen con sus flautas y con la vocería de su canto, que es menester echarlos todos por delante, para que se 
pueda lograr la música de los eclesiásticos y cantores y podernos entender con el gobierno de la procesión» (Ovalle 1969 [1646]: 285-286; Cf. Ares Queija 1984; Estenssoro 1992).

Estas formas devocionales no se limitaban, en todo caso, a la Semana Santa. De hecho, a escala menor, las formas tensionales e integrativas de esa festividad se repetían en buena parte del año. En los conventos y monasterios se organizaban, así, liturgias similares para celebrar a sus santos, advocaciones y vírgenes ligadas específicamente a cada orden y a los patronos de sus cofradías; ceremonias que se sumaban, así, a las propiamente diocesanas del calendario litúrgico anual.

Como vemos, dentro de su modestia urbana y a escala regional, Santiago de Chile reprodujo el sistema de devoción corporativa que se desplegaba en el resto del mundo colonial americano, así como las prácticas religiosas que les estaban asociadas. No obstante, como sucedía en la mayoría de estos procesos, ellos se desplegaron en medio de intercambios múltiples, desfases y transacciones, que romperán los esquemas más bien ideales diseñados por las autoridades administrativas y los cronistas religiosos como Ovalle. Y será en este contexto donde podremos observar la integración específica de indígenas provenientes del mundo andino, así como las relaciones pluriétnicas que subyacían a las procesiones descritas con anterioridad.

\section{LA INMIGRACIÓN ANDINA: DESARRAIGO Y PLURIETNICIDAD}

La presencia andina en Chile central tiene antecedentes que se vinculan con la fase expansiva del Tahuantinsuyo hacia el sur, 
cuando comenzaron a asentarse colonias de mitimaes en las riberas del río Mapocho - futuro enclave de la ciudad de Santiagocon el fin de proteger el límite meridional del imperio incaico frente a la hostilidad de los indígenas que habitaban más al sur. Casi setenta años más tarde, cientos de yanaconas, provenientes de la región del Cusco y de la meseta aimara del Collao, acompañarían las expediciones de Diego de Almagro (1535) y Pedro de Valdivia (1540) cargando alimentos y pertrechos, y apoyando militarmente a los hispanos en su invasión a Chile (Barros Arana 1999-2005 [1884-1902], I: 137; Góngora Marmolejo 1960 [c 1575]: 80; Mariño de Lobera 1960 [1580]: 241; Valdivia 1991 [1545]: 83; Villalobos 1983, I: 194).

Como sirvientes, soldados o traductores, los andinos fueron activos ayudantes de los europeos, y si bien la coerción laboral sentó las bases iniciales de la relación entre ambos grupos, lo cierto es que la rápida acomodación de los andinos a las obligaciones impuestas por los europeos, así como una actitud más bien pasiva y servil, ayudaron a que tanto los indígenas locales como los propios hispanos tendieran a verlos y a tratarlos como verdaderos colaboradores de la empresa. Su labor fue central desde un comienzo, extrayendo oro y trabajando los sembrados cuando la encomienda de autóctonos aún se encontraba en su fase embrionaria o auxiliando a los hispanos en las refriegas contra los picunches del valle central (Silva 1990: 22).

A fines del siglo XVI ya se había consolidado la presencia de estos inmigrantes en el seno de la sociedad colonial, aunque en los testamentos que varios de ellos dictaron algunas décadas más tarde observamos también un origen geográfico más variado que 
el que acompañó a los conquistadores, lo que muestra una corriente inmigratoria menos masiva, más individual, que atrajo a Chile a personas procedentes de lugares muy disímiles (Retamal Ávila 2000).

Estamos en presencia, entonces, de sujetos marcados por una gran experiencia de desarraigo. Situación vinculada, en primer lugar, a la condición de inmigrante propiamente tal, que supone el alejamiento — generalmente definitivo- de su espacio geográfico de origen, así como el traslado y, luego, el proceso de asentamiento e inserción en el lugar de destino. En segundo lugar, al menos para aquellos que no vinieron en los traslados masivos de las expediciones conquistadoras, la individualidad con la que vivieron este proceso, que implicó, a su vez, un quiebre personal con la comunidad de origen y la pérdida de lazos sociales y culturales con sus miembros. En tercer lugar, el cambio fundamental que conllevó dejar el espacio rural y aldeano, y asentarse en la complejidad de una ciudad, independientemente de si esta era más bien modesta en sus pretensiones urbanas, como Santiago de Chile. Por último, este desarraigo envuelve la necesidad vital —y evidente - de rearraigarse, de construir nuevos lazos sociales y nuevas redes materiales en el lugar de asentamiento, proceso tanto más claro en el caso de sus descendientes, que transportaron una memoria familiar foránea y, al mismo tiempo, una experiencia personal local.

\section{El papel de las cofradías}

En el contexto antes señalado, cabe preguntarse entonces sobre el papel que cupo a las cofradías en el rol tradicional que hemos 
visto al comenzar nuestra exposición, vale decir, como instancia de cohesión y de identidad social, como expresión de religiosidad y como referente de integración y de prestigio. En otras palabras, en qué medida las cofradías sirvieron como canales para integrar a la vida urbana, en particular, y al sistema colonial, en general, a dichos individuos inmigrantes. En segundo lugar, en qué forma estas corporaciones alimentaron la reconfiguración de una identidad andina en situación de inmigración. Por último, bajo qué condiciones ellas fueron, también, un reflejo de las relaciones interétnicas y pluriculturales que se tejían en aquel espacio urbano.

El problema historiográfico presentado es tan complejo como la realidad social analizada. Nuestra intención, entonces, solo será dar algunos indicios que permitan explorar estos procesos a la luz de los testamentos que dictaron algunos de aquellos inmigrantes —23 testamentos para el periodo 1564-1700_, en los que podemos detectar sus preferencias entre la variedad de cofradías que ofrecían las iglesias y conventos locales. Cabe destacar, por cierto, que se trata de un fragmento documental reducido y que la mayoría de sus actores pertenece a un sector que ha logrado cierta autonomía material, como artesanos y propietarios de solares suburbanos donde normalmente cultivan frutales, olivos y viñedos. No obstante, creemos que este fragmento nos permite percibir ciertas tendencias y sacar algunas conclusiones preliminares.

Una primera observación que podemos extraer de estos testimonios es - como ya lo habíamos adelantado- la variedad geográfica de los testantes: Cusco, Cochabamba, Jauja (Junín), 
Guayaquil, Quito, Huamanga (Ayacucho), Pudeto Viejo, Huánuco, Pisco...

En segundo lugar, aparecen allí las principales cofradías escogidas por estos indígenas, donde destaca la de Nuestra Señora de Guadalupe, establecida en la iglesia de La Merced, con una fuerte concentración de testantes andinos en la segunda década del siglo XVII. Junto con ella, también son mencionadas las de Nuestra Señora de Copacabana, establecida en la iglesia de San Francisco, y la de la Nuestra Señora de la Candelaria, en San Agustín. Algo marginalmente aparece mencionada la cofradía de Jesús Nazareno, también establecida en La Merced.

Ya tenemos, entonces, las principales cofradías en las que se asienta, sociabiliza, celebra, ahorra y se entierra la mayoría de los inmigrantes indígenas que provienen del mundo andino. No obstante, y avanzando en el objetivo de nuestra exposición, constatamos que dichos espacios no eran exclusivos de este grupo. Al contrario, también aparecen como las cofradías preferidas por otros indígenas, tanto locales como inmigrantes de otros lugares de Chile. En efecto, de un total de 16 testantes indígenas no andinos que mencionan su pertenencia a una cofradía, prácticamente todos se distribuyen entre la de Guadalupe (5), la de Copacabana (6) y la Candelaria (2). Así, las tres cofradías - todas ellas marianas, por cierto- donde se concentraba la sociabilidad religiosa de los andinos eran, en el fondo, espacios donde confluían personas de muy diverso origen geográfico y cultural, marcados por la categoría colonial de indigena. 


\section{Notas sobre Guadalupe, Copacabana y la Candelaria}

La cofradía que concentra la preferencia de los inmigrantes andinos probablemente tuvo su origen en el periplo que cumplió el monje jerónimo Diego de Ocaña (1570-1608), del monasterio español de Nuestra Señora de Guadalupe. En su corta vida, Ocaña recorrió esta parte del continente difundiendo el culto a dicha advocación y, en especial, a su imagen, que se encargó de reproducir en cada lugar visitado. Su labor de catequesis mariana comenzó en Lima, en octubre de 1599, y siguió en Chile durante 1600 (Ocaña 1995 [c 1608]: 45-46).

No sabemos con exactitud la fecha de instalación de la cofradía, aunque sin duda debió de ser en esos años, si tenemos en cuenta que ya en 1610 se establecía el contrato por medio del cual la orden mercedaria cedía «[...] la capilla que esta abaxo del coro de la dicha yglessia al entrar a mano derecha y se obliga de hazer el cuerpo y gueco della» dentro de los siguientes cuatro años, a cambio de lo cual «los dichos yndios» se comprometían a pagar 400 pesos «[...] y poner todo el demas ornato nesçessario». ${ }^{1}$ Probablemente hayan sido los mismos cofrades artesanos quienes hayan realizado esta labor, según se puede inferir del testimonio del albañil cuzqueño Rodrigo, que testa en 1612 (Retamal Ávila 2000: 136). Vemos, así, cómo los inmigrantes

1. Concierto entre el Convento de la Merced de Santiago y la Cofradía de Nuestra Señora de Guadalupe para la cesión de una capilla al interior de la iglesia (Santiago, 21 de mayo de 1610), Archivo Nacional Histórico, Escribanos de Santiago (en adelante: ANH.ES), vol. 45, fojas 209-210. 
andinos se encuentran desde el primer momento en la configuración de la corporación. De hecho, la primera mención que se tiene de sus cofrades aparece en el testamento del ayacuchano Diego Guamán, en 1610 (Retamal Ávila 2000: 133-134).

La alta concentración de aquellos indios inmigrantes denominados cuzcos - etnónimo colonial que, usado indistintamente por la sociedad santiaguina o por ellos mismos, hacía alusión a una identidad global basada en un origen geográfico vinculado al mundo andino- derivó en que prácticamente monopolizaran los cargos internos de la cofradía, «[...] nombrada de la adbocaçion de los yndios naturales y desendientes de cuzcos [...]», al menos durante sus primeros años de funcionamiento (Ruiz Rodríguez 2000: 26; ANH.ES 53: 191-191v).

Debemos llamar la atención sobre la identidad colonial de cuzco que reivindican los inmigrantes andinos y sus descendientes, toda vez que étnica y geográficamente podían ser de muy distinto origen individual. Esta diversidad se amplía si tomamos en cuenta la incorporación de indígenas chilenos —atestiguada al menos desde 1619_, quienes, a su vez, también provenían de lugares y culturas diferentes, como el valdiviano Miguel, la santiaguina Isabel de Agurto, o la cofrade María de Ahumada, que siendo natural de Córdoba, en Tucumán, era esposa del potosino Pedro Durán (Retamal Ávila 2000).

Bastante menos demandada que la cofradía anterior, en cuanto a la cantidad de inmigrantes andinos inscritos, se encuentra la de Copacabana, establecida en la iglesia de San Francisco desde antes de 1608. Según la documentación consultada, esta sería, más bien, la cofradía preferida por los indígenas locales, carac- 
terística que aparece explícita en un documento de 1613 donde esta corporación, que tenía como mayordomo a «[...] baltasar de san ffrançisco yndio[...]», había sido fundada en Santiago «[...] por los naturales della y sus términos [...]». ${ }^{2}$ Algunos años más tarde, en 1616, vuelve a señalarse esta característica en otro documento, donde Gaspar y Sancho, sus indios mayordomos, la señalan como «[...] cofradía de los indios naturales de esta ciudad $[. .]. »{ }^{3}$ Es interesante subrayar, en todo caso, que esta aparente unidad étnico-geográfica que imperaba en la cofradía - al ser de «indios naturales de esta ciudad»- era surcada por otros referentes indentitarios que la diversificaban, específicamente, el referente laboral, pues, al parecer, muchos de aquellos indios eran artesanos, y se dedicaban a especialidades distintas. Por mencionar un ejemplo, tenemos el caso del «hermano» Juan, "yndio ladino sastre», que en 1611 recibía cien pesos prestados por la cofradía gracias al apoyo de otro indio, Miguel, «sapatero diputado». ${ }^{4}$

Sin duda, la unidad cofradial de los indígenas de Copacabana solo implicaba una máscara nominal que ocultaba la gran diversidad geográfica y cultural que se escondía detrás del mundo indígena urbano, considerando que una buena parte de ellos — si no la mayoría - era también inmigrante.

2. Carta de censo de cien pesos de plata a Pedro Mancera y Mariana de Vargas otorgados por la Cofradía de Nuestra Señora de Copacabana (Santiago, 9 de enero de 1613), ANH.ES, vol. 51, fojas 19-20v.

3. Archivo del Arzobispado de Santiago, «Secretaría», vol. 61, fojas 272-275.

4. Carta de reconocimiento de deuda (Santiago, 14 de marzo de 1611), ANH.ES, vol. 41, foja $60 \mathrm{v}$. 
Jaime Valenzuela Márquez

En efecto, entre los cofrades de Copacabana que testan no solo hay personas originarias de la capital, sino también del valle central (Rapel), de la Araucanía (Villarrica) e, incluso, de la lejana isla de Chiloé. Sin ir más lejos, la primera información que encontramos de esta cofradía aparece en el testamento de un indio originario del Tucumán, en $1608{ }^{5}$ mientras que, medio siglo más tarde, su mayordomo era el zapatero quiteño Andrés Machado (Retamal Ávila 2000: 194-197; Ruiz Rodríguez 2000: 39).

En forma similar a lo sucedido con la cofradía guadalupana, la exclusividad indígena en la composición original de la de Copacabana se fue ampliando progresivamente hacia el universo mestizo e íncluso español, llegando a asentar a connotados miembros de la élite local. De hecho, en 1681 era hermano mayor de ella un comerciante español nacido en Vizcaya (Ruiz Rodríguez 2000: 30-31).

Los andinos también integraron la cofradía de la Candelaria, establecida en el convento de San Agustín hacia 1600 y con constituciones aprobadas por el obispo en 1615 (Falch 19951998). En su origen, por cierto, fue fundada por - y concebida para - negros libres, pero rápidamente adquirió un contenido biétnico al incorporar al mundo indígena de la ciudad. Así aparece indicado en sus constituciones, en las que se la definía como una entidad integrada por «mulatos orros» y por «naturales oficiales», dando cuenta, con esto último, de la preeminencia

5. Testamento de Alonso Rodríguez (La Chimba, 26 de agosto de 1608), ANH.ES, vol. 45, fojas 494-494v. 
otorgada al ingreso de indígenas que ejercieran como artesanos (Falch 1995: 26; Ruiz Rodríguez 2000: 30). Incluso, el mismo documento deja en claro que los cargos internos de la cofradía debían repartirse en igualdad de condiciones y responsabilidades entre ambas naciones, por lo que los veinticuatro aparecían conformados equitativamente por morenos y naturales, cada grupo con su respectivo mayordomo y procurador (Falch 1995: 26). Esta diferenciación étnica también se daba en el registro de género pues, al menos desde la aprobación de las constituciones, existieron «mayordomas» elegidas anualmente para «mulatas» y para «naturales» (Falch 1995).

Con respecto a la participación de inmigrantes andinos, el libro original con la documentación emanada por la Candelaria durante buena parte de la primera mitad del siglo XVII nos permite ver cómo en los veinte años que siguieron a su organización oficial, estos indígenas jugarán un rol importante en el funcionamiento interno. ${ }^{6}$ Llama la atención, en este sentido, la aparición regular de algunos de ellos entre los elegidos para administrar la institución. En efecto, ya en setiembre de aquel año asumía como mayordomo de naturales el maestro sastre

6. Es necesario destacar que, a diferencia de las otras cofradías analizadas en este artículo, donde solo encontramos fragmentos documentales que muchas veces nos obligan a conjeturar sobre la base de indicios, para la Candelaria de San Agustín contamos con este registro relativamente regular de sus elecciones entre 1612 y 1651, libro que incluye, también, algunas matrículas parciales de cofrades indígenas hombres (una lista de los asentados antes de $1633 \mathrm{y}$, luego, los asientos nuevos y pagos anuales de 1633,1637 y 1640) y mujeres (asientos nuevos y pagos anuales de 1620, 1622, 1630, 1639, 1640 y 1643): fojas $43-45$ y $53-54 \mathrm{v}$, respectivamente. 
Juan de Luna, «indio del cuzco», a quien dos años antes lo encontramos arrendando un solar en el sector de la Chimba. ${ }^{7}$ En 1615 también fue elegido como alférez el sedero y sombrerero, originario de Huánuco, Andrés Banado Pongo. En 1616, por su parte, aparece como procurador de la cofradía otro andino, el aimara Augustín Quispe. El siguiente año, 1617, será cuando Banado se posicione como mayordomo de naturales, cargo en el que será reelegido sucesivamente hasta comienzos de 1619. En este año vemos aparecer a Francisco Cuzco como alférez, del que no poseemos más datos, pero cuyo origen andino se hace evidente a través de su patronímico. En la siguiente elección, llevada a cabo a comienzos de 1622, el cargo de alférez recaerá en otro andino, Diego Quispe, probablemente un pariente de quien había sido procurador en 1616. A comienzos de 1623 regresa Andrés Banado como mayordomo, quien fue reemplazado al año siguiente por el mencionado Diego Quispe.

Dentro de esta dinámica, quisiéramos destacar el declive paralelo que al interior de la cofradía sufre el estamento de los morenos, pues desde comienzos de la década de 1630 escasean los cofrades elegibles para ocupar los cargos reservados a su nación. Esta situación hace crisis en la elección de mayordomos de 1633, momento en que se determinó que, en adelante, fuese uno solo el mayordomo en funciones. Junto con él se eligiría un diputado «[...] de diferente nación de la del mayordomo [...]», al que le tocaría asumir en el periodo siguiente, de acuerdo con un sistema

7. Arriendo de un solar en la Chimba de Juanes de Herrera a Juan de Luna (Santiago, 9 de julio de 1613), ANH.ES, vol. 46, foja 56. 
de turnos. Pues bien, realizada la votación de ese año por todos los cofrades, salió elegido, como hemos visto, el sastre andino Juan de Luna, pese a que el año anterior también había sido un andino, Andrés Banado, quien había ejercido el cargo en el turno de los pardos. ${ }^{8}$ Con ello se comprueba la influencia predominante de estos inmigrantes al interior de la Candelaria, incluso más allá del sector propiamente indígena de la institución, pues también votaron por él los morenos.

Otro aspecto que debemos subrayar es que también observamos en la Candelaria aquella bispanización de su contenido, con la llegada de mestizos y españoles que, ya desde la década de 1620, comenzaron a cambiar la orientación biétnica inicial. La creciente presencia de hispanos e hispanas los llevó incluso a buscar posicionarse como un núcleo en similares condiciones políticas con las otras naciones, intención que se concretó en 1634 con las cofradas que eligieron a su «Hermana mayor de las españolas». $\mathrm{Al}$ año siguiente, no obstante, los estamentos tradicionales - morenos y naturales - reaccionarían determinando que los españoles podían tener voto activo, pero no podían ser elegidos en los cargos cofradiales. ${ }^{?}$

8. Auto y elección de mayordomo (23 de enero de 1633) y actas de elecciones de mayordomos y oficiales (1 de enero de 1632), «Libro de la Cofradía de Nstra. Sra. de la Candelaria, en el Convento de San Agustínı (1606-1651), fotocopia del original en el Archivo del Convento de San Agustín (original en AAS), fojas $58-59$ y 181 , respectivamente.

9. Elecciones de mayordomos y oficiales, "Libro de la Cofradía...», fojas 181-184. 


\section{REDES SOCIALES, VINCULACIONES ESPACIALES Y ETNICIDAD (A MODO DE CONCLUSIÓN)}

Como hemos visto en cada una de las cofradías estudiadas, estas se construyeron como espacios que integraban a una gran diversidad de personas con orígenes sociales, étnicos y geográficos muy distintos. Los indios andinos inmigrantes que experimentaban entre ellos esa misma diversidad, pero que eran vistos por la sociedad chilena - y se presentaban a sí mismos- con una identidad común basada, justamente, en la identificación con el espacio andino, llegaron a formar parte de esos canales corporativos de devoción, muchas veces en sus rangos fundacionales y dirigentes.

Las cofradías se instalaron, así, en medio de la complejidad étnica y de la multiplicidad de referentes identitarios de la población urbana, con lo que se dio un nuevo sentido de pertenencia institucional -en este caso, religiosa - a sus variados integrantes. Bajo esta perspectiva podemos verlas como un espacio de integración pero en un contexto despersonalizado, caracterizado por identidades étnicas fragmentadas, desarraigadas o amestizadas, propias de un contexto urbano colonial (Valenzuela Márquez 1999; Bernand y Gruzinski 1993: 250-285; Mansilla 2008).

En el caso de Santiago, ayudaría, además, el hecho de que, a diferencia de lo que sucedía en otros lugares, prácticamente no existían cofradías vinculadas a gremios de artesanos específicos -quizás, justamente, porque no existían estos gremios, en el sentido institucional del término, sino artesanos-. Así, las cofradías santiaguinas también se erigían como canalizadoras de una devo- 
ción transversal en términos laborales al incorporar en su seno a artesanos de diversos oficios y latitudes.

Según este prisma de fragmentación, podríamos entonces confirmar el papel de las cofradías en el despliegue exitoso de un sistema como el hispano que, luego de producir dichos quiebres -fruto de los procesos demográficos, sociales, laborales, culturales y políticos que implicó la propia organización colonial-, ahora ofrecía canales de integración simbólica y de pertenencia social que terminaban siendo funcionales para su legitimación colectiva (Valenzuela Márquez 2001).

Sin embargo, desde un prisma que privilegie la construcción de redes y referentes comunes, en forma paralela a las instituciones ofrecidas por el sistema, hay algunos indicios que nos permiten descifrar ciertas tendencias en relación con algunas pautas relacionales entre - al menos - parte de sus miembros. En efecto, si cruzamos el contenido gremial de sus integrantes con el lugar donde residen en la ciudad, observamos ciertas coincidencias que abren nuevas e interesantes preguntas. Así, observamos que entre los fundadores de la cofradía de los nazarenos -otra donde se asientan indígenas inmigrantes-, al lado del zapatero andino Hernando Muñoz se encontraba el sastre mestizo Juan Chico de Peñalosa. Eran cofrades durante esos primeros años, también, el herrero Mateo Naranjo, el cuchillero Manuel González Guimaraes, el espadero portugués Pedro González y los carpinteros Juan Bernal y Juan de Lepe, entre otros artesanos. ${ }^{10}$

10. Emma de Ramón 2004: 100; Poder para testar de Pedro González, espadero (Santiago, 27 de febrero de 1613), ANH.ES, vol. 51, fojas 116-116v. 
Tenemos, entonces, un primer eje común entre todos ellos - ser artesanos - bajo el cual subyacen las relaciones interétnicas definidas por el origen distinto de, al menos, Muñoz (Huánuco) y González (Lisboa).

No obstante, si enfocamos nuestra mirada en Juan Chico, podemos observar que dichas relaciones tenían más puntos en común que los aparentes. En efecto, si bien el sastre era originario de Concepción, estuvo casado algún tiempo con Isabel de Gálvez, hija mestiza de una indígena originaria de Quito. Su vinculación con el mundo andino era tal, que conocía perfectamente la lengua quechua, tanto, que en una oportunidad concurrió como traductor a la casa de su vecino, el indio cuzqueño Gaspar Guanca, albañil que no hablaba castellano y que deseaba dictar su testamento al sentir cercana su muerte. Tenemos así a dos artesanos (sastre y albañil) que comparten una cercanía cultural con el mundo andino (lengua, familia, etc.), pero que, además, viven en un mismo sector de la ciudad, la Chimba, vocablo de origen quechua que aludía al barrio del otro lado del rio, en este caso, del Mapocho.

El espacio de habitación constituye, pues, un eje adicional que debemos incluir en el análisis de la complejidad social y étnica que hemos estado observando respecto de los indígenas andinos, de su participación en las cofradías y, en un sentido más amplio, de su integración en la vida urbana de Santiago. Así podemos identificar a núcleos de personas en quienes confluye su lugar de residencia - la Chimba- y poseen una cofradía en común - la Candelaria - en el trío formado por el hijo de «cuzca» Lorenzo Ramírez Yañez y los andinos Pedro Lima y 
Andrés Banado Pongo. Sus oficios, por cierto, eran vinculantes en la medida en que los dos primeros ejercían como sastres y Banado era sedero y sombrerero. Por lo demás, uno de los albaceas del testamento de Lima será, justamente, Banado, a quien denomina como «my compadre» (Retamal Ávila 2000: 166-167).

El sector de la Chimba comenzó a consolidarse a principios de la década de 1560, justamente con el asentamiento de algunos de los yanaconas andinos que habían venido al servicio de los conquistadores. De hecho, la mayoría de los matrimonios de naturales registrados en las últimas décadas del siglo XVI y que declaran habitar en dicho barrio son, justamente, de indígenas andinos (De Ramón 1965: 232; Thayer Ojeda 1905: 102).

No obstante, como ya adelantamos, este no fue un espacio exclusivo de esos inmigrantes. Fue también el lugar que albergó la diversidad étnica de la ciudad, pues se asentaron allí otros indígenas de variada procedencia - mapuches del sur, huarpes de Cuyo, juríes del Tucumán-, negros libertos y ladinos, hispanocriollos pobres y la amplia gama de mestizos que nacieron de sus uniones. Era en ese sector extraurbano, entonces, en su vida cotidiana y laboral, donde cristalizaron las relaciones interétnicas que luego veremos reflejadas en las prácticas desplegadas al interior de la ciudad, particularmente en la composición y organización de las cofradías religiosas.

Así, las experiencias de la inmigración, de la inserción en un contexto urbano definido por reglas del sistema colonial español, de la integración económica y de la interacción profunda y cotidiana con los otros que habitaban la ciudad permitirán a los indígenas andinos de Santiago un arraigo sobre la base de nuevos 
tejidos comunitarios y corporativos - como las cofradías-, de nuevas identidades sociales y culturales y, eventualmente, de nuevos referentes étnicos —el uso del etnónimo cuzco es un ejemplo-, situación que podríamos estudiar como un proceso de etnogénesis urbana (Schwartz y Salomon 1999; Boccara 2001; Martínez 2004).

\section{REFERENCIAS}

Ares Queija, Berta

1984 «La danza de los indios: un camino para la evangelización del virreinato del Perú». Revista de Indias, n. ${ }^{\circ} 174$, pp. $445-463$.

Barros Arana, Diego

1999 [1884] Historia general de Chile. Vol. I. Santiago: Editorial Universitaria-DIBAM, Centro de Investigaciones Diego Barros Arana.

BAZARTE, Alicia

1998 «Las limosnas de las cofradías: su administración y destino». En: Pilar Martínez López-Cano (et al., eds.). Cofradias, capellanias y obras pias en la América colonial. México: Universidad Nacional Autónoma de México, pp. 65-74.

Bernand, Carmen y Serge GruZinski

1993 Histoire du Nouveau Monde. Vol. II. «Les métissages (15501640)». París: Fayard. 
BOCCARA, Guillaume 2001

«Mundos nuevos en las fronteras del Nuevo Mundo». Nuevo Mundo. Mundos Nuevos. Fecha de consulta: 27/02/2009. <http://nuevomundo.revues.org/document 426.html>.

Celestino, Olinda y Albert Meyers

1981a Las cofradias en el Perú: región central. Francfort: Verlag Klaus Dieter Vervuert.

1981b «La dinámica socioeconómica del patrimonio cofradial en el Perú colonial: Jauja en el siglo XVII». Revista Española de Antropología Americana, vol. XI, pp. 183-206.

Chance, John y William B. TAYlor

1985 "Cofradías and Cargos: An Historical Perspective on the Mesoamerican Civil-Religious Hierarchy». American Etbnologist, vol. 12, n. ${ }^{\circ}$, pp. 1-26.

Charney, Paul

1998

«A Sense of Belonging: Colonial Indian Cofradías and Ethnicity in the Valley of Lima, Perus. The Americas, vol. 54, n. 3 , pp. 379-407.

DE RAMÓn, Armando

1965 «Bautizos de indígenas según los libros del Sagrario de Santiago correspondientes a los años 1581-1596». Historia, n. ${ }^{\circ}$, pp. $229-235$.

DE RAMÓN, Emma

2004 «Juan Chico de Peñalosa, Sebastián de Iturrieta y Martín García, tres sastres en los albores de la industria santia- 
guina: 1560-1620». En: Julio Retamal Ávila (ed.). Estudios coloniales III. Santiago: Universidad Andrés Bello, pp. 95-112.

ESTENSSORO, Juan Carlos

1992

«Los bailes de los indios y el proyecto colonial». Revista Andina, n. ${ }^{\circ}$, año 10 , pp. 353-389.

2003

Del paganismo a la santidad. La incorporación de los indios del Perú al catolicismo, 1532-1750. Lima: IFEA-Instituto Riva-Agüero.

FALCH, Jorge 1995-1998 «Cofradía de Nuestra Señora de la Candelaria de los mulatos en el Convento de San Agustín de Santiago de Chile». En: Anuario de Historia de la Iglesia en Chile, 1. ' parte, n. ${ }^{\circ} 13$, 1995, pp. 17-30; 2. ${ }^{a}$ parte, n. ${ }^{\circ} 16,1998$, pp. 167-199.

Góngora Marmolejo, Alonso de

1960 [1575] «Historia de Chile desde su descubrimiento hasta el año de 1575». En: Francisco Esteve Barba (ed.). Crónicas del reino de Chile. Vol. 131. Madrid: Biblioteca de Autores Españoles.

LAVRÍN, Asunción

1998 «Cofradías novohispanas: economías material y espirituab. En: Pilar Martínez López-Cano (et al., eds.). Cofradías, capellanias y obras pias en la América colonial. México: Universidad Nacional Autónoma de México, pp. 49-64.

MANSILLA, Judith 2008 «Exteriorizando la religiosidad: los "indios ricos" en su lucha por el manejo de la capilla de la Virgen de Copacabana». Ponencia presentada en el VII Congreso Inter- 
nacional de Etnohistoria. Lima: Pontificia Universidad Católica del Perú, agosto de 2008.

MARiÑo DE Lobera, Pedro

1960 [1580] «Crónica del Reino de Chile, escrita por el capitán D. Pedro Mariño de Lobera..., reducido a nuevo método y estilo por el padre Bartolomé de Escobar, de la Compañía de Jesús». En: Francisco Esteve Barba (ed.). Crónicas del reino de Chile. Vol. 131. Madrid: Biblioteca de Autores Españoles.

MARTÍNEZ, José Luis

2004 «Cómo hablar de indios e identidades en el siglo XVI? Una aproximación a la construcción de los discursos coloniales». Historia Indígena, n. ${ }^{\circ}$, pp. 41-55.

OCAÑA, Diego de

1995 [1608] «Viaje a Chile», fragmento del texto $A$ través de la América del Sur. Santiago: Universitaria.

Ovalle, Alonso de

1969 [1646] Histórica relación del reino de Chile y de las misiones y ministerios que ejercita en él la Compañia de Jesús. Santiago: Universidad de Chile-Instituto de Literatura Chilena.

Retamal Ávila, Julio

2000 Testamentos de «indios» en Chile colonial: 1564-1801. Santiago: Universidad Andrés Bello-RIL Editores.

Ruiz Rodríguez, Carlos 2000

«Cofradías en Chile Central. Un método de evangelización de la población indígena, mestiza y criolla». Anuario de Historia de la Iglesia en Chile, n. ${ }^{\circ} 18$, pp. 23-58. 
Jaime Valenzuela Márquez

SCHWARTZ, Stuart y Franck SALOMON

$$
\begin{aligned}
& \text { «New Peoples and New Kinds of People: Adaptation, } \\
& \text { Readjustment, and Ethnogenesis in South American Indi- } \\
& \text { genous Societies (Colonial Era)». En: Frank Salomon y } \\
& \text { Stuart B. Schwartz (eds.). The Cambridge History of the Native } \\
& \text { Peoples of the Americas. Vol. III. Cambridge-Nueva York: } \\
& \text { Cambridge University Press, 1. }{ }^{\text {a }} \text { parte, pp. 443-501 }
\end{aligned}
$$

Silva, Osvaldo

«Aproximaciones al estudio del mestizaje en Chile entre los siglos XVI y XVII». En: Sonia Pinto (ed.). Familia, matrimonio y mestizaje en Chile colonial. Santiago: Universidad de Chile.

Thayer OJeDA, Tomás

1905

Santiago durante el siglo XVI. Constitución de la propiedad urbana $i$ noticias biográficas de sus primeros pobladores. Santiago: Imprenta Cervantes.

Valdivia, Pedro de

1991 [1545] «Carta de Pedro de Valdivia a Hernando Pizarro (La Serena, 4 de septiembre de 1545)». En: Cartas de don Pedro de Valdivia que tratan del descubrimiento y conquista de la Nueva Extremadura. Santiago-Barcelona: Andrés Bello-Lumen, pp. 82-94.

\section{VALenZuela MárqueZ, Jaime}

1999

«Une société dépersonnalisée? Ordre colonial et référents identitaires à Santiago du Chili au XvIIe siècle». En: Bernard Lavallé (ed.). Transgressions et stratégies du métissage en Amérique coloniale. París: Presses de la Sorbonne Nouvelle, pp. 139-163. 
INDIOS ANDINOS EN COFRADIAAS CHILENAS

2001

Las liturgias del poder. Celebraciones públicas y estrategias persuasivas en Chile colonial (1609-1709). Santiago: Dirección de Bibliotecas, Archivos y Museos, Centro de Investigaciones Diego Barros Arana-LOM Ediciones.

2007

«El terremoto de 1647: experiencia apocalíptica y representaciones religiosas en Santiago colonial». En: Jaime Valenzuela Márquez (ed.). Historias urbanas. Homenaje a Armando de Ramón. Santiago: Universidad Católica de Chile, pp. 27-65.

VILLALOBOS, Sergio

1983 Historia del pueblo cbileno. Vol. I. Santiago: Zig-Zag. 